\title{
Forecasting Spanish GDPs with Spectral Analysis
}

\author{
Pierre Rostan ${ }^{a}$, AleXANDra Rostan ${ }^{\text {a }}$ \\ a Prince Sultan University, Department of Finance, Rafaha Street, Salah Ad Din,P.O. Box 66833, \\ Riyadh, 11586 Kingdom of Saudi Arabia.E-mail: pierre@psu.edu.sa, arostan@aucegypt.edu
}

\begin{abstract}
The paper emphasizes the recent use of spectral analysis for forecasting financial and economic time series which deserves consideration from econometricians. Time series of Spanish nominal and real GDPs are decomposed in simpler signals called approximations and details in the framework of the one-dimensional discrete wavelet analysis. The simplified signals are recomposed after Burg extension. 2017-2026 forecasts with spectral analysis are less optimistic than the ones of government agencies. Benchmarking spectral analysis to an ARIMA model show the pertinence of adding spectral analysis to the battery of tools used by econometricians and quantitative analysts for the forecast of economic time series.
\end{abstract}

Keywords: GDP, Spectral Analysis, ARIMA, Forecasting.

\section{Previsiones del PIB español con análisis espectral}

\begin{abstract}
RESUMEN
El artículo enfatiza el uso del análisis espectral para labores de predicción con series temporales económicas y financieras, que ha merecido la consideración de los económetras. Las series temporales del PIB nominal y real se descomponen en señales más simples denominadas aproximaciones y detalles en el marco del análisis de wavelets discretas unidimensionales. Las señales simplificadas se recomponen después de la extensión de Burg. Las previsiones para el periodo 2017-2016 derivadas del análisis espectral son menos optimistas que las proporcionadas por la agencia gubernamental. De la comparación del análisis espectral con la modelización ARIMA se deriva la pertinencia de incorporar el análisis espectral a la batería de instrumentos utilizados por los económetras y los analistas cuantitativos para labores de previsión de series temporales económicas.
\end{abstract}

Palabras Clave: PIB, Análisis Espectral, ARIMA, Previsión.

JEL Classification: C53, E37

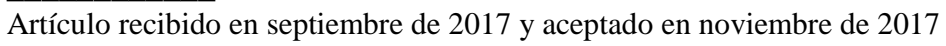

Artículo disponible en versión electrónica en la página www.revista-eea.net, ref. ə-36102 


\section{INTRODUCTION}

Spectral analysis is a branch of Physics which models physical phenomena such as electrical, audio or seismic signals which propagate through space in waveforms. In recent years, spectral analysis has been applied to time series outside the field of Physics. A first attempt was presented in Estudios de Economía Aplicada to appraise the financial sustainability of the Spanish pension system using Spanish population forecasts (Rostan et al., 2015). Spectral analysis was then applied to yield curve forecasting (Rostan et al., 2017) with a robust outcome when compare to historical data and benchmarked to the Diebold and Li (2006) model. With a refined methodology using multiscale principal component analysis to take into account the co-dynamics of age groups, Rostan and Rostan (2017a) forecasted European and Asian populations with spectral analysis which lead to original outcomes when compare to more conformist population projections of the United Nations. Finally, the versatility of spectral analysis applied to the forecast of financial times series with distinctive properties was illustrated with market data in Rostan and Rostan (2017b).

The originality of the present paper is to apply spectral analysis to economic time series of the Spanish nominal and real GDPs, and to show the robustness of the method when benchmarked to the more conventional ARIMA technique.

Regarding the Spanish economy, while traveling in Asia and Europe these past two years, the authors noted the resurgence of Spanish tourists compare to previous years. Whichever country visited by the authors on these two continents (e.g. Indonesia, Thailand, Laos, Myanmar, France, Hungary, Serbia, Greece or Italy), the major group of tourists besides Chinese was Spanish. We were wondering the reason of this affluence of Spaniards going sightseeing until we realized that the Spanish economy has rebounded since 2013. Spain's economy, the fourth largest in the euro zone, has been one of the fastest growing since then (White, 2017). In 2017, strong exports and domestic demand have boosted the Spanish economy back to the size it was before the 2008 financial crisis. This paper will present some projections of the Spanish economy.

Section 2 presents the methodology. Section 3 gathers the results and section 4 concludes.

\section{METHODOLOGY}

The objective of the paper is to illustrate an application of spectrum analysis to the forecast of economic time series, the Spanish nominal and real nominal GDPs. As a benchmark, nominal and real nominal GDPs of the Euro area are also forecasted. Figure 1 illustrates annual data of Spanish and Euro area GDPs 
from 1960 to 2016. As observed, Spanish and Euro area nominal GDPs are highly correlated, the correlation coefficient being equal to $99.19 \%$.

Figure 1

Time series of the Spanish nominal GDP (left axis) and the Euro area nominal GDP (right axis) from 1960 to 2016 (57 data each). Source: World Bank, https://data.worldbank.org/country/spain

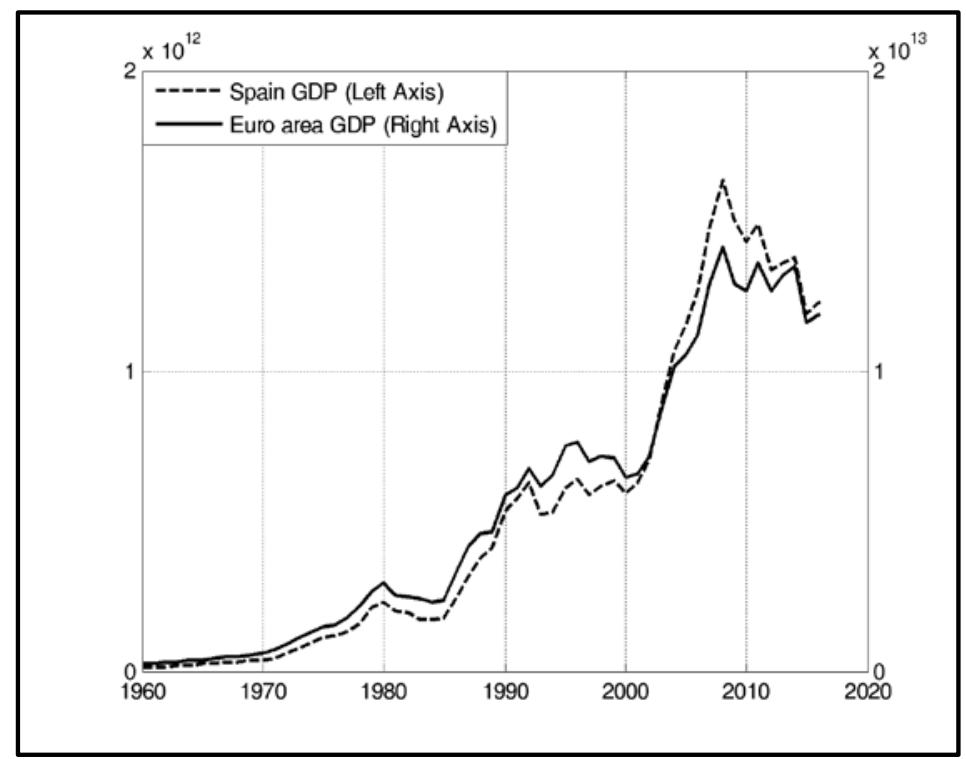

Source: Own elaboration.

\subsection{Step 1: interpolating data}

Figure 2

Time series of the nominal Spanish GDP, initial time series (57 points) and interpolated time series with cubic spline (5,601 points).

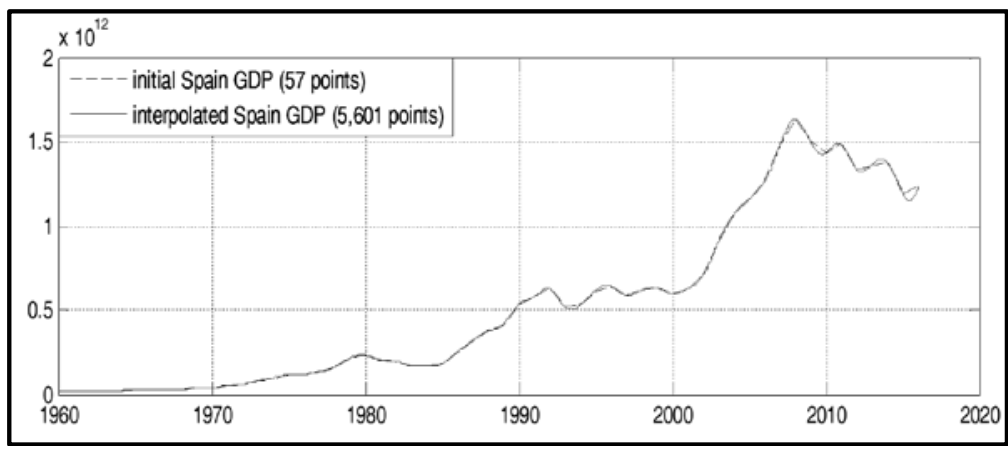

Source: Own elaboration. 
From the World Bank economic database, we retrieve Spanish and Euro area GDPs between 1960 and 2016 illustrated in Figure 1. We interpolate the 57 historical annual data with 5,601 observations using cubic spline interpolation. The reason for interpolating is that wavelet decomposition requires downsampling, costly in terms of data. It requires a number of data greater than the initial 57 GDP values. We set therefore the time interval $d t$ to 0.010 year in order to generate 5,601 points.

\subsection{Step 2: wavelet decomposition}

We decompose the signal, the interpolated time series of the Spanish nominal GDPs (5,601 points) obtained at step 1, into decomposed signals $c A s$ named approximations and $c D s$ named details. The discrete wavelet transform is a kind of decomposition scheme evaluated by passing the signal through lowpass and highpass filters (Corinthios, 2009), dividing it into a lower frequency band and an upper band. Each band is subsequently divided into a second level lower and upper bands. The process is repeated, taking the form of a binary, or "dyadic" tree. The lower band is referred to as the approximation $c A$ and the upper band as the detail $c D$. The two sequences $c A$ and $c D$ are downsampled. The downsampling is costly in terms of data: with multilevel decomposition, at each one-level of decomposition the sample size is reduced by half (in fact, slightly more than half the length of the original signal, since the filtering process is implemented by convolving the signal with a filter. The convolution "smears" the signal, introducing several extra samples into the result). Therefore, the decomposition can proceed only until the individual details consist of a single sample. Thus, the number of levels of decomposition will be limited by the initial number of data of the signal. It is the reason why we have interpolated the initial Spanish GDP into 5,601 data. The level of decomposition of the signal is left to the appreciation of the user. Rostan and Rostan (2017b), applying the decomposition to a non-stationary time series, recommended an optimal $6^{\text {th }}$-level decomposition. Figure 3 illustrates the $6^{\text {th }}$ level decomposition of the Spanish nominal GDP (5,601 points). We observe in Figure 3 that details $D$ s are small and look like high-frequency noise, whereas the approximation $A 6$ contains much less noise than does the initial signal. In addition, the higher the level of decomposition, the lower the noise generated by details. For a better understanding of signal decomposition using discrete wavelet transform, please refer to the methodology section of Rostan and Rostan (2017b). 
Figure 3

$6^{\text {th }}$-level decomposition of the Spanish nominal GDP $(5,601$ interpolated data) using onedimensional discrete wavelet analysis

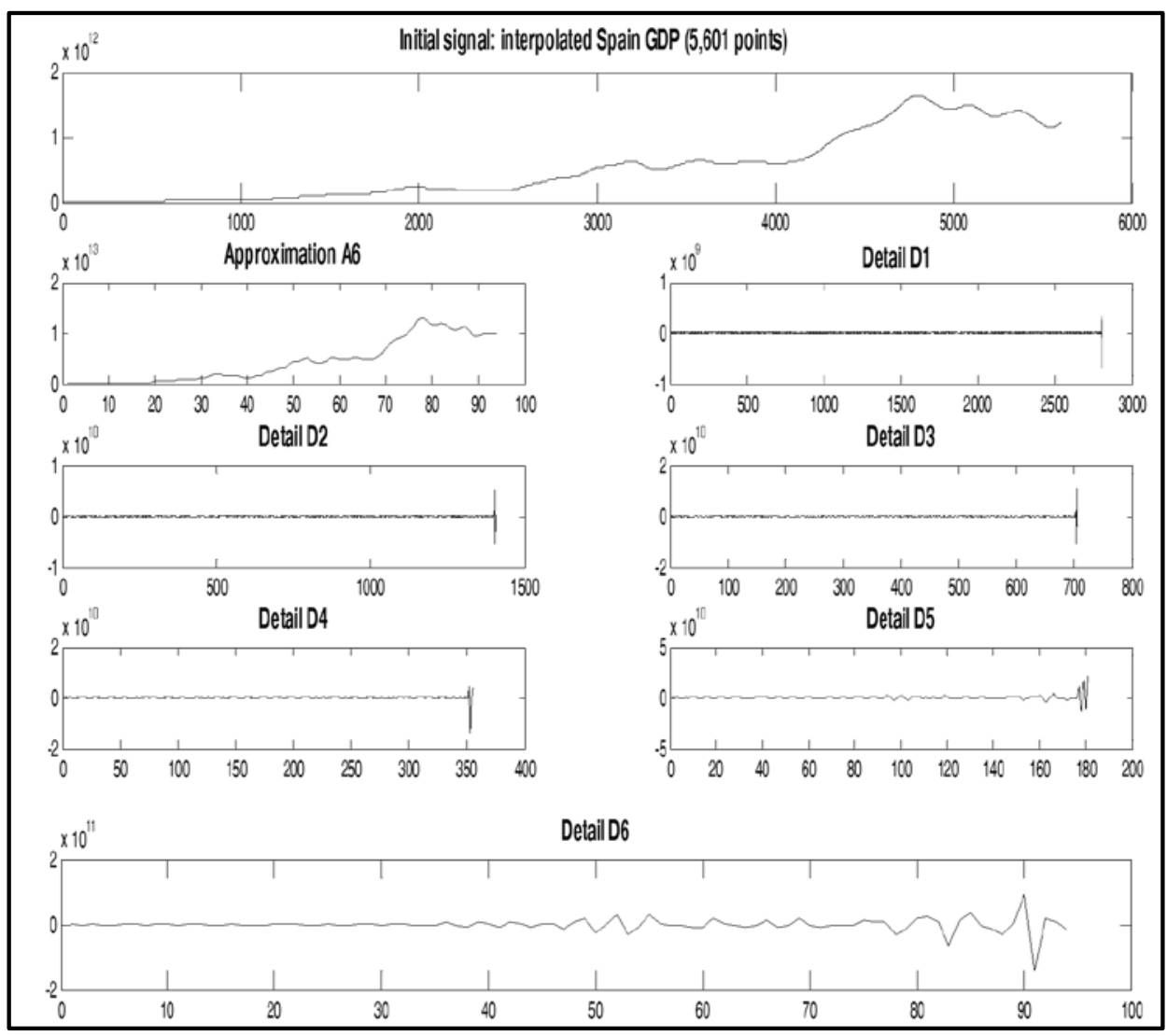

Source: Own elaboration.

\subsection{Step 3: Burg extension of approximations and details}

We apply Burg extension to $c A$ and $c D$ as presented in Figure 5. To run the Burg extension, we apply an autoregressive $p$ th order from historical data, in this paper we choose a $p$ th order equal to the longest available order when forecasting. For instance in 2016, when forecasting nominal GDPs for the subsequent years, the longest $p$ th order available is 5571 out of 5601 historical interpolated data. Given $x$ the decomposed signal (which is $c A$ or $c D$ ), we generate a vector $a$ of all-pole filter coefficients that model an input data sequence using the Levinson-Durbin algorithm (Levinson, 1946; Durbin, 1960). We use the Burg (1975) model to fit a pth order autoregressive (AR) model to the input signal, $x$, by minimizing (least squares) the forward and backward prediction errors while constraining the $A R$ parameters to satisfy the Levinson- 
Durbin recursion. $x$ is assumed to be the output of an $A R$ system driven by white noise. Vector $a$ contains the normalized estimate of the $A R$ system parameters, $A(z)$, in descending powers of $z$ :

$$
H(z)=\frac{\sqrt{e}}{A(z)}=\frac{\sqrt{e}}{1+a_{2} z^{-1}+\ldots+a_{(p+1)} z^{-p}}
$$

Since the method characterizes the input data using an all-pole model, the correct choice of the model order $p$ is important. In Figure 4, the prediction error, $e(n)$, can be viewed as the output of the prediction error filter $A(z)$, where $H(z)$ is the optimal linear predictor, $x(n)$ is the input signal, and $(n)$ is the predicted signal.

Figure 4

Prediction error filter to run the Burg extension

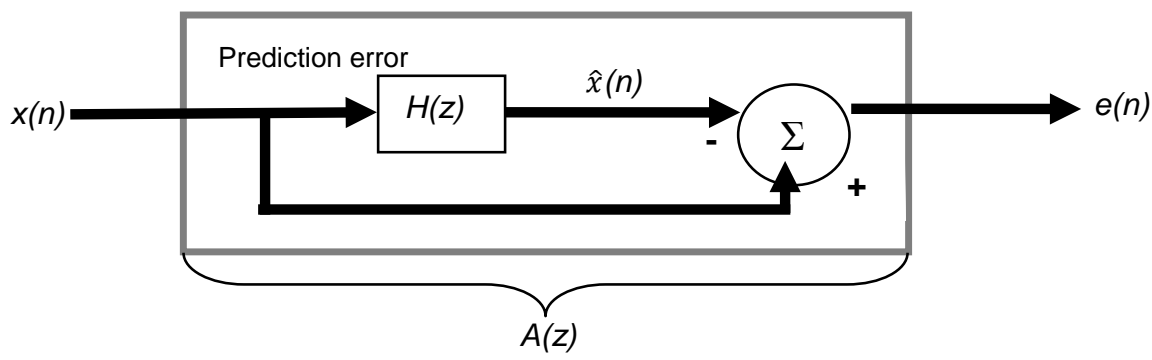

In a last step, the Infinite Impulse Response (IIR) filter extrapolates the index values for each forecast horizon. IIR filters are digital filters with infinite impulse response. Unlike finite impulse response (FIR) filter, IIR filter has the feedback (a recursive part of a filter) and is also known as recursive digital filter.

\subsection{Step 4: wavelet reconstruction}

We recompose the forecasted signal after Burg extension using the methodology illustrated in Figure 5. To simplify the demonstration, we present a $3^{\text {rd }}$-level decomposition/reconstruction diagram. 
Figure 5

Diagram of a 3rd-level wavelet decomposition/reconstruction tree to forecast the initial signal $s(t)$

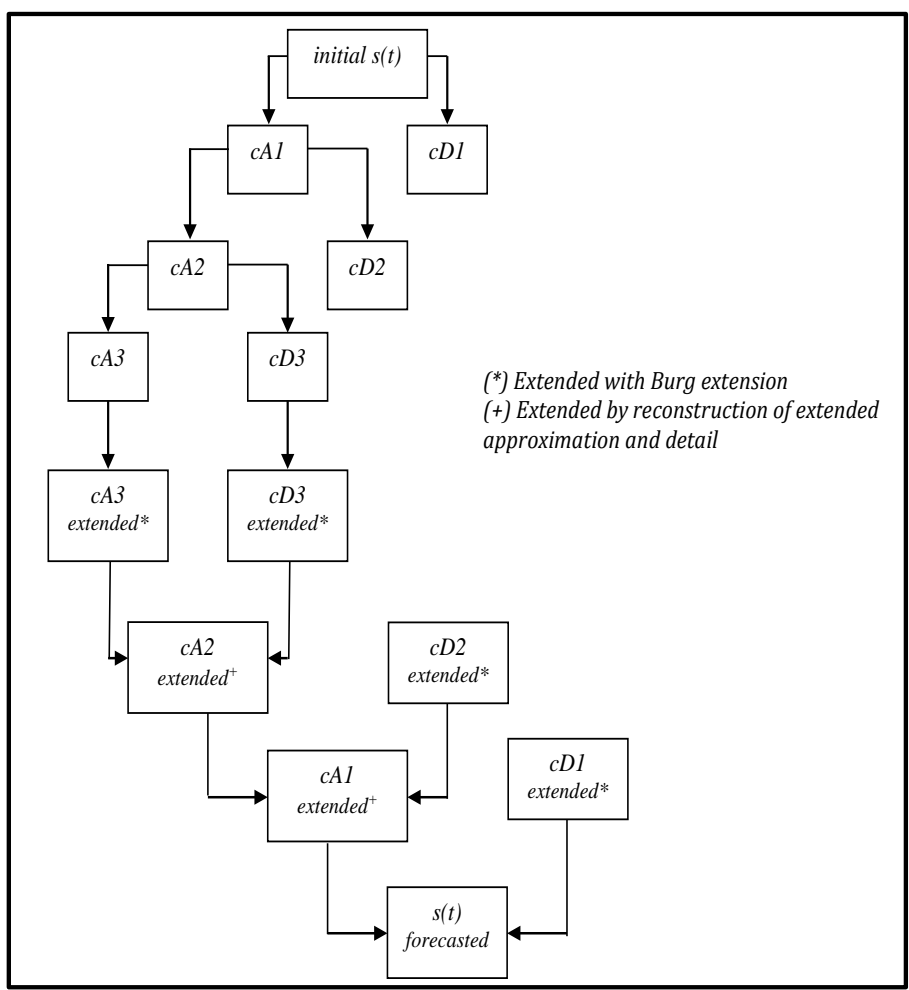

Source: Own elaboration.

\subsection{Step 5: assessing the forecasting ability of spectrum analysis}

To assess the forecasting ability of spectrum analysis applied to the time series of the Spanish nominal GDP, we evaluate the forecasts over 10 years by step of 10 years. The forecasting periods are non-overlapping. We benchmark spectrum analysis to the ARIMA forecasting model (Box and Jenkins, 1976; Baillie and Bollerslev, 1992; Box et al., 1994) applied to the absolute level of nominal GDP (i.e. no decomposition of the time series). We use the Root Mean Error Square criteria (forecasts versus historical data) to compute the error of forecasting.

The forecasting periods extend from 1971 to 2016 (46 years).

The reasons of using ARIMA as benchmark model are twofold:

1) In practice, many economic time series are nonstationary such as nominal and real Spanish GDPs, so that the characteristics of the underlying stochastic processes change overtime (Pindyck and Rubinfield, 1998). By choosing an 
order of integration of order $d$, we transform the nonstationary series into stationary. The Augmented Dickey-Fuller test is applied to the Spanish GDP time series before and after differencing and leads to the conclusion that before differencing, the two time-series are nonstationary (i.e. existence of a unit root) and after differencing the series are stationary (rejection of the existence of a unit root).

We say that $y_{t}$ is homogeneous nonstationary of order $d$ if $w_{t}=\Delta^{d} y_{t}$ is a stationary series with $\Delta$ denoting differencing, i.e. $\Delta y_{t}=y_{t}-y_{t-1}, \Delta^{2} y_{t}=\Delta y_{t}-\Delta y_{t-1}$ and so forth. We can get back to nonstationary time series after forecasting by summing $w_{t}$ a total of $d$ times. We write this as $y_{t}=\Sigma^{d} w_{t}$.

Thus, forecasting a stationary time series offers better forecast accuracy than forecasting nonstationary time series due to the fact that characteristics of its underlying stochastic process do not change overtime.

2) To choose the ARIMA model that best fits the data of the Spanish GDPs time series, we identify the ARMA lags $p$ and $q$ by applying the Bayesian information criterion (BIC) to the Spanish nominal GDP time series after interpolation (5,601 data). For this purpose, we estimate several models with different $p$ and $q$ values. For each estimated model, we compute the loglikelihood objective function value. Then, we input the loglikelihood value to compute the BIC measure of fit which penalizes for complexity. This methodology is implemented in Matlab using the econometrics toolbox.

Figure 6

Sample autocorrelation function (ACF) and partial autocorrelation function (PACF) of the historical daily S\&P 500 Composite index time series from December 11, 1996 to January, 302009 (3,168 data)

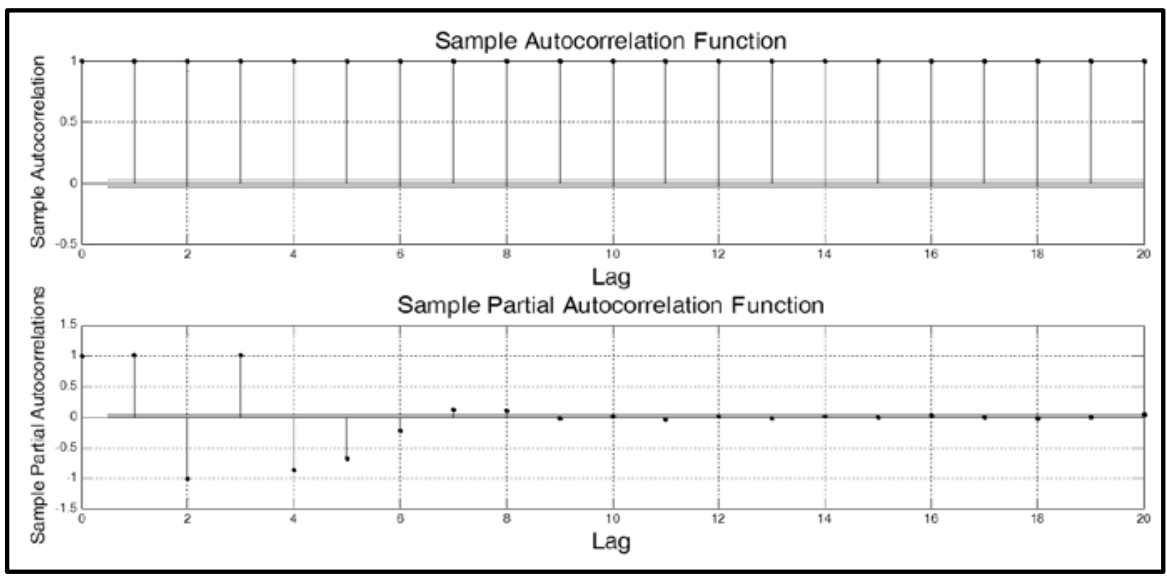

Source: Own elaboration.

In Figure 6, we plot the sample autocorrelation function and the partial 
autocorrelation function of the Spanish nominal GDPs time series illustrated in Figure 2 from 1960 to 2016 (5,601 data).

The sample ACF decays very slowly, which is consistent with an ARMA model. We can have a rough idea of the ARMA lags by looking at the PACF. It appears than no more than eight AR or MA terms are required.

To formally identify the ARMA lags, we fit several models with different lag choices, making the degree of differencing (i.e. the "I" of ARIMA) varying from 0 to 8 . We fit all combinations of ARMA(p,q) for $\mathrm{p}=1, \ldots, 8$ and $\mathrm{q}=1, \ldots, 8$ (a total of 64 models per degree of differencing) when possible. We store the loglikelihood objective function and number of coefficients for each fitted model. We calculate the BIC for each fitted model. We obtain the following four output BIC matrices for no differencing, the first, second and third order differencing. In the four output BIC matrices below, the rows correspond to the AR degree (p) and the columns correspond to the MA degree (q). The best values in the BIC matrices are the smallest BIC value.

1) No differencing: The non-seasonal autoregressive polynomial is unstable for $\mathrm{p}$ and $\mathrm{q}$ higher than 3 , else:

$$
\begin{array}{rrr}
1.0 \mathrm{e}+05 * \mathrm{q} & \\
2.4151 & 2.4057 & 2.4039 \\
\mathrm{p} 3.1285 & 3.1233 & 3.1222 \\
3.1283 & 3.1230 & 3.1223
\end{array}
$$

Selected model: ARIMA(p,d,q) = ARIMA(1,0,3).

Average RMSE on five in-sample forecasting periods from 1971 to 2016 (46 years): $2.16 \mathrm{E}+11$

2) First order differencing: The non-seasonal autoregressive polynomial is unstable for $\mathrm{p}>4$ and $\mathrm{q}>3$, else:

$$
\begin{aligned}
& 1.0 \mathrm{e}+05 * \mathrm{q} \\
& \begin{array}{lll}
1.9529 & 1.9432 & 1.9419
\end{array} \\
& \text { p } \quad \begin{array}{llll}
1.5607 & 1.5507 & 1.5694
\end{array} \\
& \begin{array}{lll}
1.5611 & 1.5762 & 2.3971
\end{array} \\
& 1.5545 \quad 2.3973 \quad 2.3972
\end{aligned}
$$

Selected model: ARIMA(p,d,q) = ARIMA(2,1,2).

Average RMSE: $2.38 \mathrm{E}+11$

3) Second order differencing: The non-seasonal autoregressive polynomial is unstable for $\mathrm{p}>3$ and $\mathrm{q}>2$, else:

$$
\begin{array}{rrr}
1.0 \mathrm{e}+05 * & \mathrm{q} \\
& 1.5415 & 1.5305 \\
\mathrm{p} & 1.9376 & 1.4367 \\
1.4365 & 1.4251
\end{array}
$$

Selected model: ARIMA(p,d,q) = ARIMA(3,2,2). 
Average RMSE: 2.19E+12

4) Third order differencing:

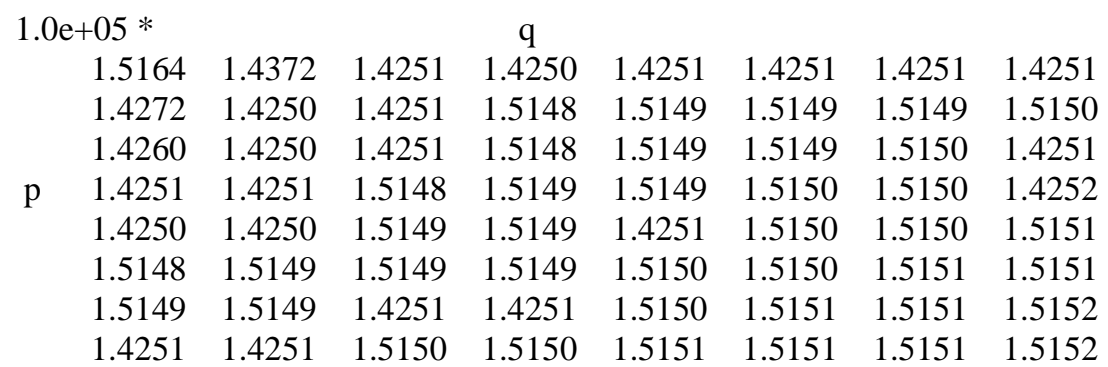

Selected model: ARIMA(p,d,q) = ARIMA(1,3,4).

Average RMSE: $4.28 \mathrm{E}+12$

The best value in the BIC matrix (third order differencing) is the smallest BIC value equal to $1.0 \mathrm{e}+05 * 1.4250$ in the $(1,4)$ position. This value appears several times in the matrix, but to keep the model simple based on the 'Keep It Sophistically Simple' rule the choice of ARIMA $(1,3,4)$ model is optimal for forecasting the Spanish GDP.

One important outcome concerning the assumption made earlier that 'forecasting a stationary time series offers a better forecast accuracy than forecasting nonstationary time series due to the fact that characteristics of its underlying stochastic process do not change overtime' does not hold in our case since ARIMA model with no differencing offers a lower RMSE (2.16E+11) than the first order differencing model (RMSE equal to 2.38E+11). In the Result section, we illustrate in Figure 11 the forecasts of ARIMA(1,0,3) corresponding to the model with no differencing with the lowest average RMSE for the five insample forecasting periods.

\subsection{Step 6: building $95 \%$ confidence interval for the forecasts generated by spectrum analysis and ARIMA(1,0,3)}

We build a 95\% confidence interval for the forecast $Y_{F}$ :

$$
\begin{aligned}
& \hat{Y}_{F}=Y_{F} \pm t_{0.025} s_{F} \\
& s_{F}^{2}=s^{2}\left[1+\frac{1}{n}+\frac{\left(X_{F}-\bar{X}^{2}\right)}{\sum\left(X_{i}-\bar{X}^{2}\right)}\right] \\
& \text { with } s=\sqrt{\frac{1}{n} \sum_{i=1}^{n}\left(y_{o b s}-y_{F}\right)^{2}}
\end{aligned}
$$

$t$ refers to the $t$ distribution with $n-2$ degrees of freedom.

The standard deviation $s_{F}$ is computed from $2 * 600$ interpolated data between 
2011 and 2016 from observed and forecasted nominal GDP.

\section{RESULTS}

The objective of the paper is to illustrate an application of spectrum analysis to the forecast of Spanish nominal and real GDPs. We illustrate the 10-year forecasts of the Spanish nominal GDP in Figure 7. We repeat the exercise with the Euro area nominal GDP as a benchmark.

\section{Figure 7}

Starting at the vertical dot line (2016), 10-year forecasts with spectral analysis from 2017 to 2026 of the Spanish nominal GDP (left axis) and the Euro area nominal GDP (right axis). Source of historical data: World Bank, https://data.worldbank.org/country/spain

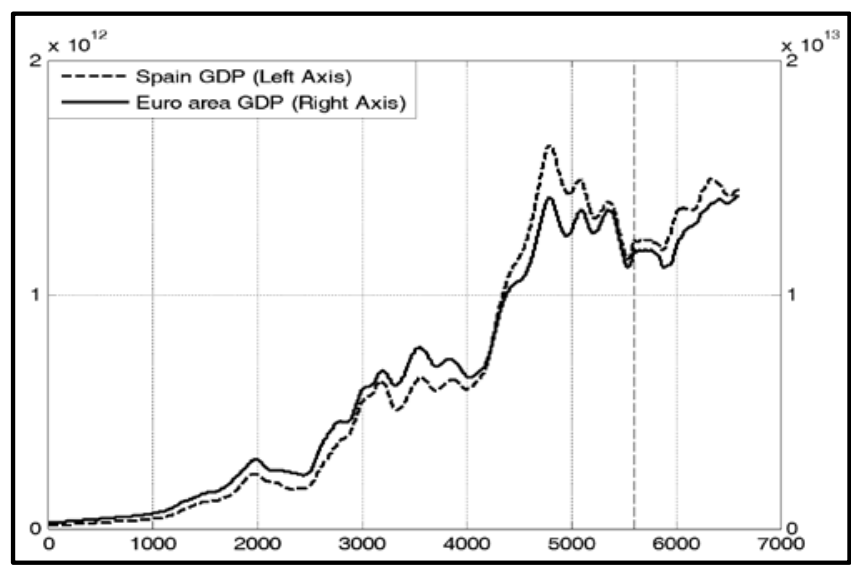

Source: Own elaboration.

From Figure 7, the Spain nominal GDP projection obtained with spectral analysis starting at the vertical dot line (2016) shows a slowdown in activity in Spain, then a rally of the economic activity in 2020 (at the 6000-X-axis line) that builds up during the 6 following years (2021 to 2026), reaching in 2026 the 2010 GDP-level of Spain.

Building a 95\% confidence interval for the Spanish nominal GDP forecasts based on step 6 of the methodology section, we draw Figure 8 and Figure 9 using respectively spectrum analysis and ARIMA(1,0,3) model. 
Figure 8

Starting at the vertical dot line (2016), 10-year forecasts with spectral analysis from 2017 to 2026 of the Spanish nominal GDP with a 95\% confidence interval. Source of historical data: World Bank, https://data.worldbank.org/country/spain

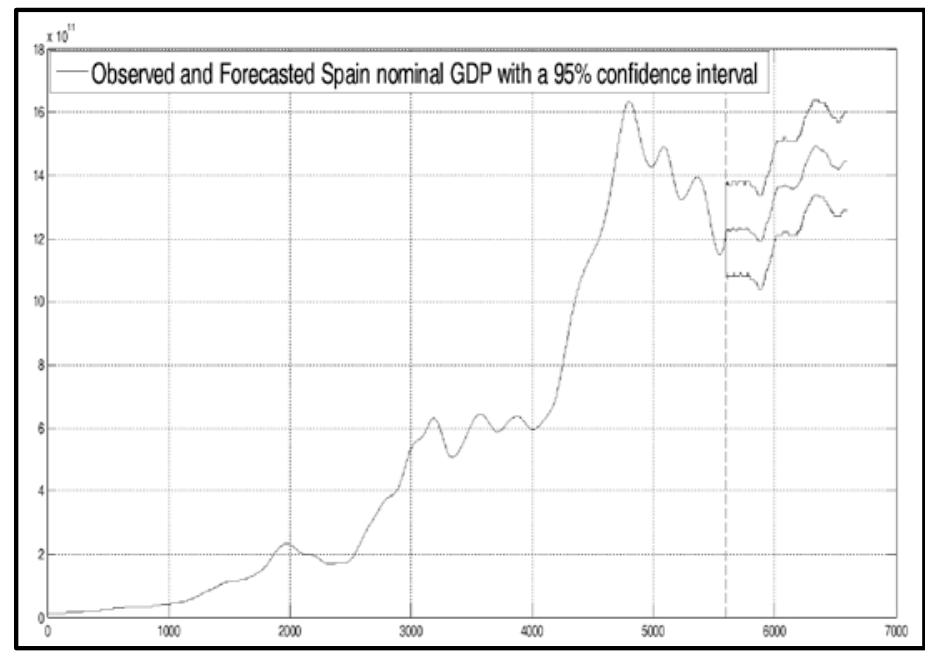

Source: Own elaboration.

Figure 9

Starting at the vertical dot line (2016), 10-year forecasts with ARIMA(1,0,3) from 2017 to 2026 of the Spanish nominal GDP with a 95\% confidence interval. Source of historical data: World Bank, https://data.worldbank.org/country/spain

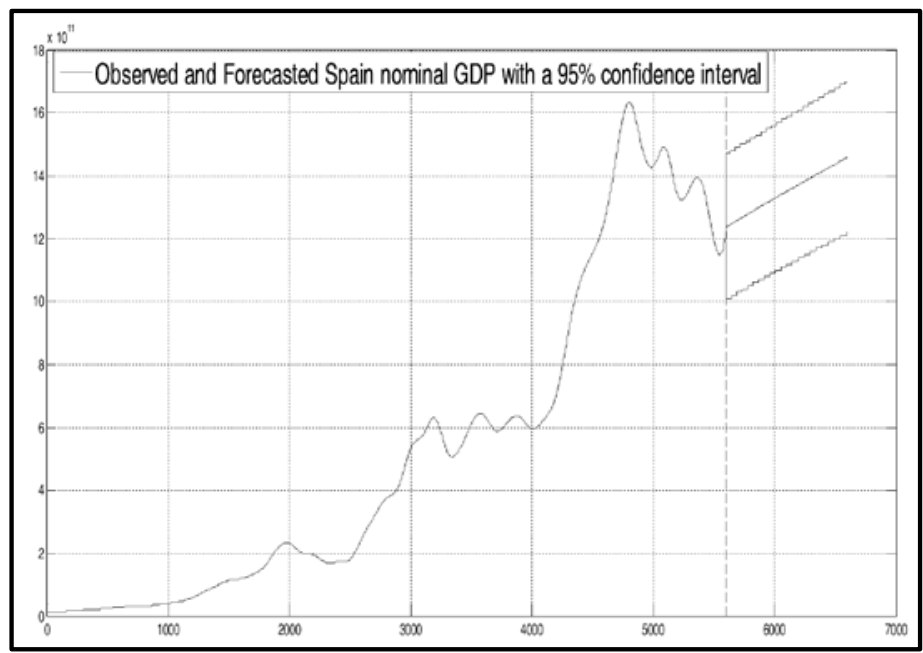

Source: Own elaboration.

To provide a more accurate picture of the Spanish economy, we forecast the 
Spanish real GDP with spectral analysis illustrated in Figure 10.

Figure 10

Starting at the vertical dot line (2016), 10-year forecasts with spectral analysis from 2017 to 2026 of the Spanish real GDP in US constant 2000 dollars (inflation-adjusted). Source of historical data: World Bank on http://www.multpl.com/spain-real-gdp/table/by-year

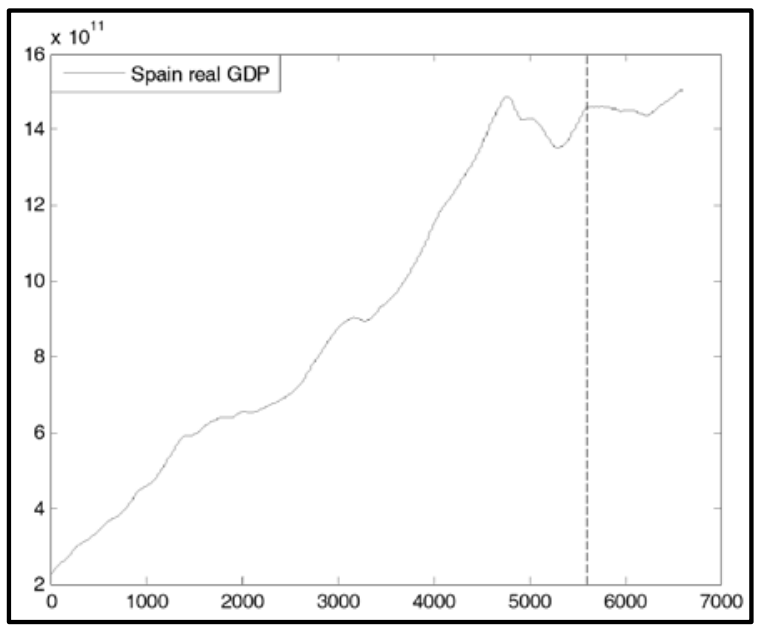

Source: Own elaboration.

Recent economic reports based on Spain real GDP are optimistic about the Spanish economy. The New York Times (2017) pictures a very positive outlook of the Spanish economy: Spain's economy has returned to its pre-crisis size (2008-level), according to data released by the Spanish government in July 2017. In Barcelona harbor (Catalonia) for instance, thousands of containers full of factory wares are loaded on ships bound for points across Europe and Asia. Spain has seen its economy lifted by exports. Tough economic reforms made easier for Spanish employers to fire workers, thus making them more willing to hire. However, it is worth noticing that the Spanish government carries enormous debt, reaching 100 percent of the economy's annual output. This debt reflects the cost of having paid out unemployment benefits during the crisis and having bailed out crippled banks. Government investment in infrastructure remains also weak. The unemployment rate is still high, above 18 percent with near 39 percent for younger workers. 4.25 million people out of 47 million are unemployed. The political risk in Spain is also very high, with a referendum project of independence of Catalonia which could cost 20\% of the GDP to Spain since Catalonia GDP represents about one fifth of the nation GDP. We may look at the shining economic statistics released by the Spanish Government in 2017 as part of an operation of propaganda to counter the momentum initiated by the Catalan independence movement. It should be therefore wiser to look for confirmation of 
these dazzling economic data before confirming a trend in the Spanish economic reprise at the 2008 pre-crisis level that seems surprisingly optimistic. From Figure 10, spectral analysis forecasts a Spanish real GDP value in 2017 lower than the 2008-level (1.46 billion versus 1.48 billion) and stagnation until mid-2023 when it will rebound then reach an historical high in 2026 (1.51 billion).

Concerning the Euro area economy, the growth spurt sped up in Q2 2017, with the economy growing at the fastest pace in over two years (Bouzanis, 2017). Netherlands was the top performer in the second quarter. The impressive result was underpinned by falling unemployment, a thriving housing market and high consumer sentiment. Spain also witnessed growth, with the economy that returned to near pre-crisis levels. Activity was steady in Austria and Slovakia, but slowed in Belgium, Cyprus, Germany, Latvia, Lithuania and Portugal. Meanwhile, growth was also stable in major players France and Italy compared to the previous period. Leading indicators point to another quarter of buoyant activity, and 'Focus Economics' analysts see GDP rising a healthy 0.5\% in Q3.

\section{Figure 11}

Starting at the vertical dot line (April 1 2017), 10-year forecasts (39 forecasted quarters) with spectral analysis from July 12017 to January 12027 of the Euro area (19 countries) real GDP in US Quarterly Units, Chained 2010 Euros, Seasonally Adjusted. The historical data are quarterly and extend from January 11995 to April 12017 (90 data).

Source of historical data: Federal Reserve Bank of Saint Louis on https://fred.stlouisfed.org/series/CLVMEURSCAB1GQEA19

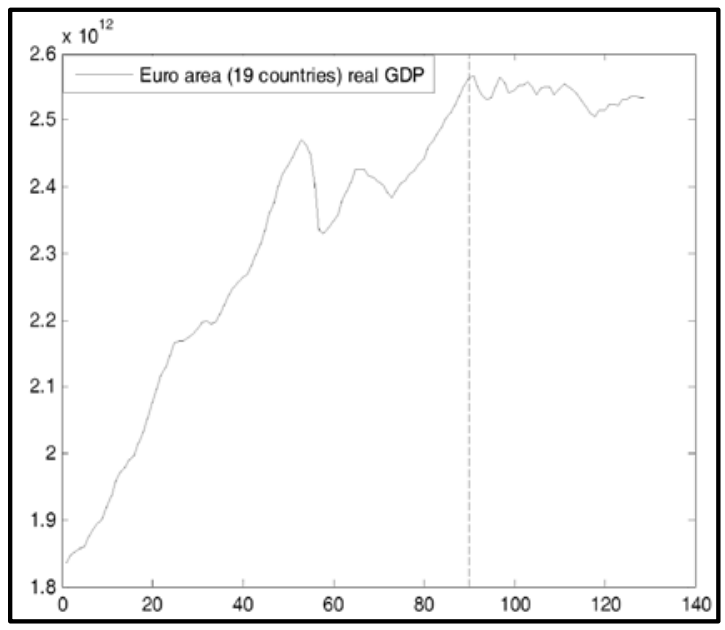

Source: Own elaboration.

The political risk has retroceded in recent months in the Euroarea. Based on Bouzanis report (2017), the fastest-growing economies are expected to be Ireland and Luxembourg this year, expanding at rates of $4.0 \%$ or above. On the 
other end of the spectrum, Greece and Italy will be the region's laggards, both growing at around $1.0 \%$. Among the remaining major economies in the region, Spain will outperform the rest with 3.0\% growth. Germany is seen expanding $1.9 \%$, followed by France at $1.5 \%$.

Based on an optimistic report of the European Commission (2017), 'the European economy has entered its fifth year of recovery, which is now reaching all EU Member States. This is expected to continue at a largely steady pace this year and next. For the first time in almost a decade, the economies of all EU Member States are expected to grow throughout the entire forecasting period (2016, 2017 and 2018). However, the outlook is surrounded by higher-thanusual uncertainty.'

Based on Figure 7 (spectral analysis forecasts of the nominal GDP of the Euro area) nominal GDP shows a slowdown in activity in the Euro zone for the next three years (2017 to 2019), then a rally of the economic activity in 2020 (at the 6000-X-axis line) that builds up during the 6 following years (2021 to 2026), overshooting in 2026 the 2008-level of the Euro area. However, based on Figure 11 (spectral analysis forecasts of the Real GDP of the Euro area), the real GDP will reach an historical high in Q3 2017. Then, the real GDP will fluctuate with a clear downtrend until Q2 2024, then it will rebound and follow an uptrend until 2026 reaching a level below 2017 (2.53 billion versus 2.57 billion in 2017). In conclusion, Figure 11 illustrates the Euro area recovery announced by the European Commission until Q3 2017 but spectral analysis forecasts are clearly less optimistic than the European Commission forecasts for the subsequent quarters.

Finally, we assess the forecasting ability of spectrum analysis applied to the time series of the Spanish nominal GDP. We measure the forecasting error over 10 years by step of 10 years. The forecasting periods are non-overlapping. We benchmark spectrum analysis to the ARIMA $(1,0,3)$ forecasting model (Box and Jenkins, 1976; Baillie and Bollerslev, 1992; Box et al., 1994) applied to the absolute level of nominal GDP (i.e. no decomposition of the time series). The choice of the ARIMA $(1,0,3)$ is explained in section 2.5. We use the Root Mean Error Square criteria (forecasts versus historical data) to compute the error of forecasting. The forecasting periods extend from 1971 to 2016 (46 years).

Table 1 gathers the RMSE values for each forecasting period and model.

Table 1

RMSE values for each forecasting period and model

\begin{tabular}{|ccccccc|}
\hline Forecasted Period & $\mathbf{1 9 7 1 - 1 9 8 0}$ & $\mathbf{1 9 8 1 - 1 9 9 1}$ & $\mathbf{1 9 9 1 - 2 0 0 0}$ & $\mathbf{2 0 0 1 - 2 0 1 0}$ & $\mathbf{2 0 1 1 - 2 0 1 6}$ & Average RMSE \\
\hline Spectral Analysis & $6.73 \mathrm{E}+10$ & $7.40 \mathrm{E}+10$ & $7.54 \mathrm{E}+10$ & $2.91 \mathrm{E}+11$ & $5.05 \mathrm{E}+10$ & $1.12 \mathrm{E}+11$ \\
\hline ARIMA(1,0,3) & $9.81 \mathrm{E}+10$ & $8.56 \mathrm{E}+10$ & $5.98 \mathrm{E}+11$ & $5.64 \mathrm{E}+11$ & $2.73 \mathrm{E}+11$ & $2.16 \mathrm{E}+11$ \\
\hline
\end{tabular}

Source: Own elaboration. 
Figures 12 and 13 illustrate the 10-year forecasts with respectively Spectral Analysis and ARIMA(1,0,3) model based on interpolated data obtained at step 1 of the methodology.

Figure 12

10-year Spectral Analysis Forecasts of Spain Nominal GDP versus observed Nominal GDP

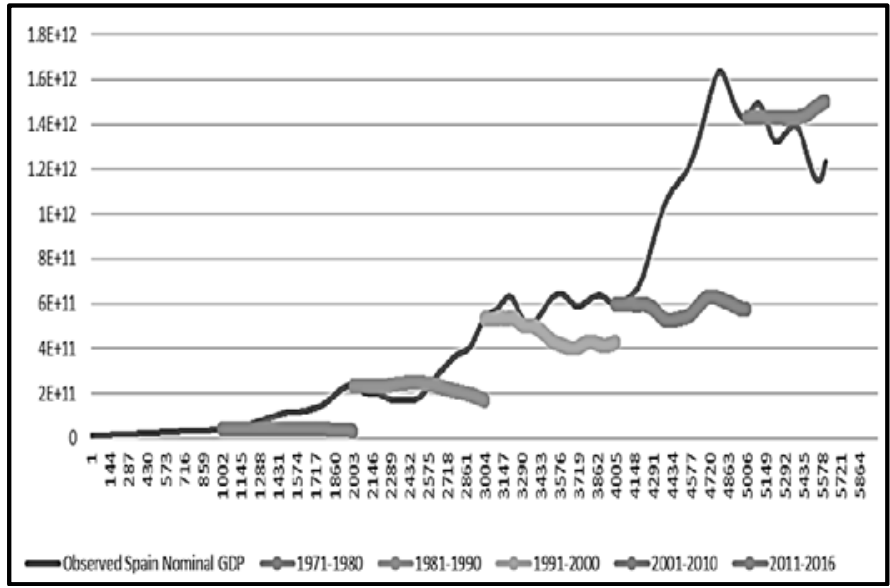

Source: Own elaboration.

The RMSE criteria and the observation of Figures 12 and 13 demonstrate the clear superiority of Spectral Analysis over the ARIMA $(1,0,3)$ model to forecast the Spanish nominal GDP over 10-year periods.

Figure 13

10-year ARIMA $(1,0,3)$ Forecasts of Spain Nominal GDP versus observed Nominal GDP

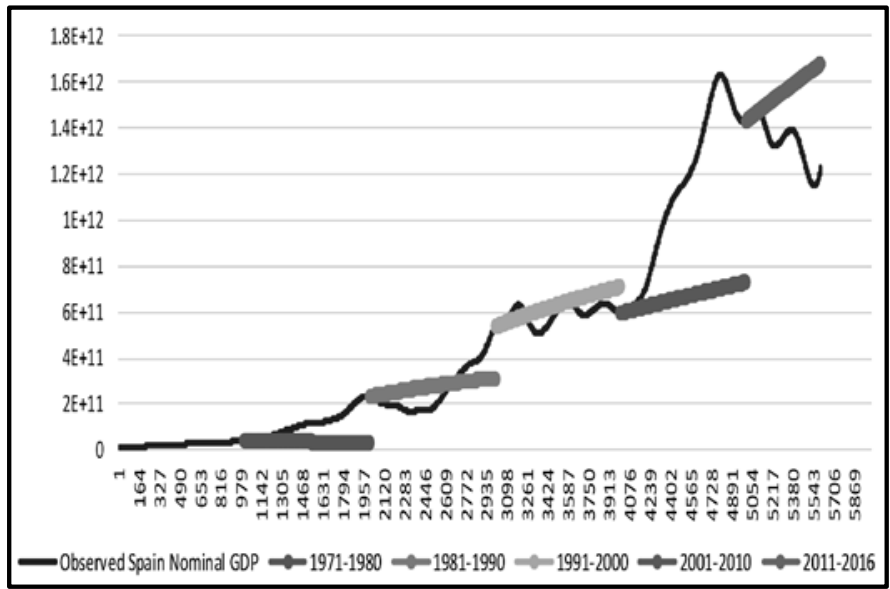

Source: Own elaboration. 


\section{CONCLUSION}

The objective of the paper is to illustrate an application of spectrum analysis to the forecast of economic time series, Spanish nominal and real GDPs. We benchmark the forecasts to Euro area nominal and real GDPs forecasts. Regarding the methodology, time series are decomposed in simpler signals called approximations and details in the framework of the one-dimensional discrete wavelet analysis. The simplified signals are recomposed after Burg extension. 2017-2026 forecasts with spectral analysis for both Spanish and Euro area economies are less optimistic than the ones of government agencies.

To demonstrate the preeminence of Spectral Analysis versus ARIMA forecasting model, we generate forecasts over 10-year non-overlapping horizons of the Spanish nominal GDP with both models. Results show the pertinence of adding spectral analysis to the battery of tools used by econometricians and quantitative analysts for the forecast of economic time series.

\section{BIBLIOGRAPHY REFERENCES}

BAILLIE R and BOLLERSLEV T. (1992). "Prediction in Dynamic Models with TimeDependent Conditional Variances". Journal of Econometrics, 52(9), pp. 1-113.

BOUZANIS A. (2017). "Economic Snapshot for the Euro Area." Focus Economics. Available at: https://www.focus-economics.com/regions/euro-area [24 September 2017].

BOX GEP and JENKINS GM. (1976). Time Series Analysis: Forecasting and Control, Revised Edition. San Francisco: Holden Day.

BOX GEP, JENKINS GM and REINSEL GC. (1994). Time Series Analysis: Forecasting and Control, 3rd ed. Englewood Cliffs, NJ: Prentice Hall.

BURG JP. (1975). "Maximum Entropy Spectral Analysis". Available at: http://sepwww.stanford.edu/theses/sep06/ [24 September 2017].

CORINTHIOS M. (2009). Signals, Systems, Transforms, and Digital Signal Processing with MATLAB. Boca Raton, FL: Taylor and Francis Group, LLC CRC Press.

DIEBOLD F and LI C. (2006). "Forecasting the term structure of government bond yields" Journal of Econometrics, 130, pp. 337-364.

DURBIN J. (1960). "The fitting of time series models" Revue de I'Institut International de Statistique, 28, pp. 233-44.

EUROPEAN COMMISSION (2017) "Economic forecasts". Available at: https://ec.europa.eu/ info/business-economy-euro/economic-performance-and-forecasts/economicforecasts_en [24 September 2017].

LEVINSON N. (1946). "The Wiener RMS (root mean square) error criterion in filter design and prediction" Journal of Mathematical Physics, 25, pp. 261-78. 
NEW YORK TIMES (2017). Spain's Long Economic Nightmare Is Finally Over". Available at: https://www.nytimes.com/2017/07/28/business/spain-europe-economyrecovery-unemployment.html?mcubz=0 [24 September 2017].

PINDYCK RS and RUBINFIELD DL. (1998). Econometric models and economic forecasts, 4th ed. Boston, MA: Irwin McGraw-Hill.

ROSTAN P, BELHACHEMI R and ROSTAN A. (2015). "Appraising the financial sustainability of a pension system with signal processing" Estudios de Economía Aplicada, 33, pp. 1-16.

ROSTAN P, BELHACHEMI R and RACICOT, FE. (2017). "Forecasting the yield curve with the Burg model" Journal of Forecasting, 36(1), pp. 91-99. DOI: 10.1002/for.2416. Available at: http://onlinelibrary.wiley.com/doi/10.1002/for.2416/full [24 September 2017].

ROSTAN P and ROSTAN A. (2017a). "Population Projections and Pension System Sustainability". Saarbrücken (Germany): Lambert Academic Publishing, 80 pages. ISBN 978-620-2-06479-8

ROSTAN P and ROSTAN A. (2017b). "The forecasting ability of spectrum analysis with financial time series" Accepted for publication in The Journal of Forecasting.

WHITE S. (2017). "Exports help brighten outlook for Spanish economy" Reuters. Available at: http://www.reuters.com/article/us-spain-gdp/exports-help-brighten-outlook-forspanish-economy-idUSKBN18L1CD [24 September 2017]. 